\title{
Regulation of the heat stress response in Arabidopsis by MPK6-targeted phosphorylation of the heat stress factor HsfA2
}

So far little is known on the functional role of phosphorylation in the heat stress response of plants. Here we present evidence that heat stress activates the Arabidopsis mitogen-activated protein kinase MPK6. In vitro and in vivo evidence is provided that MPK6 specifically targets the major heat stress transcription factor HsfA2. Activation of MPK6 results in complex formation with HsfA2. MPK6 phosphorylates HsfA2 on T249 and changes its intracellular localisation. Protein kinase and phosphatase inhibitor studies indicate that HsfA2 protein stability is regulated in a phosphorylation-dependent manner, but this mechanism is independent of MPK6. Overall, our data show that heat stress-induced targeting of HsfA2 by MPK6 participates in the complex regulatory mechanism how plants respond to heat stress. 


\section{Introduction}

Due to their sessile life style, plants are constantly subjected to a variety of biotic and abiotic stresses in their environment. To survive under these conditions, complex signalling networks developed which allow terrestrial plants to efficiently sense and respond to stressful conditions. In particular, temperatures above the optimum are sensed as heat stress, which disturbs cellular protein homeostasis. Accumulation of heat shock proteins (Hsps) are an essential part of the heat stress response and are assumed to play a central role in acquired thermotolerance in plants and other organisms (Baniwal et al, 2004; Hartl and Hayer-Hartl, 2002; Haslbeck, 2002; Kotak et al, 2007b; Morimoto, 1998; Nakamoto and Vígh, 2007; Wang et al, 2004). The central regulators of the expression of heat stress-responsive genes are the heat stress transcription factors (Hsfs) (Baniwal et al, 2004; Kotak et al, 2007a; Miller and Mittler, 2006; Morimoto, 1998; Nover et al, 1997; Scharf et al, 1998b; Schöffl et al, 1998; von Koskull-Döring et al, 2007).

It was shown that the transcriptional activity of mammalian Hsf1 is regulated by phosphorylation (Knauf et al, 1996; Kline and Morimoto, 1997; Holmberg et al, 2001). So far, 5 phosphorylation sites have been characterized for mammalian Hsf1: S230, S303, S307, S326 and S363 (Chu et al, 1996). During non-stress conditions Hsf1 is a monomer and phosphorylated at S303, S307, S326 and S363, which results in repression of DNA-binding capacity and transcriptional activity. During heat stress Hsf1 shuttles to the nucleus, assembles in heat stress granules, trimerizes and binds to heat stress elements. Ultimately, after phosphorylation of S230, It leads to 
transcriptional activation of Hsp genes (Holmberg et al, 2001, Morimoto, 1998; Pirkkala et al, 2001).

Another well investigated heat stress transcription system is that of yeast Hsf1 (ScHsf1) (Sorger and Pelham, 1988; Sorger, 1991). ScHsf1 is phosphorylated in response to heat shock and oxidative stress (Sorger et al, 1987; Høj and Jacobsen, 1994) while the phosphorylation state of this Hsf regulates both activation and inactivation of the transcription activation function (Hashikawa and Sakurai, 2004). A C-terminal modulator domain (CTM) is essential for activation of heat stress element-containing genes but also for hyperphosphorylation of the ScHsf1 during heat stress. The serine and threonine residues of the CTM are constitutively phosphorylated under normal conditions. After heat shock further phosphorylation is induced (Sorger, 1990).

In contrast to yeast and Drosophila with a single Hsf and mammals with up to four Hsfs, the plant Hsf family with $20-30$ members is more complex (Baniwal et al, 2004, von Koskull-Döring et al, 2007). The Arabidopsis Hsf family consists of 21 members belonging to three classes A, B and C (Nover et al, 2001, Baniwal et al, 2004, von Koskull-Döring et al, 2007). From Arabidopsis, several Hsfs have been functionally characterized in more detail but so far nothing is known about their regulation by posttranslational modification (Baniwal et al, 2007; Charng et al, 2007; Czarnecka-Verner et al, 2000, 2004; Davletova et al, 2005; Hübel and Schöffl, 1994; Hübel et al, 1995; Kim and Schöffl, 2002; Kotak et al, 2007a; Li et al, 2005; Lohmann et al, 2004; Nishizawa et al, 2006; Panchuk et al, 2002; Prändl et al, 1998; Reindl and Schöffl, 1998; Schramm et al, 2006; Wunderlich et al, 2003). 
Mitogen-activated protein kinases (MPKs) show a similar complexity of 20 genes in Arabidopsis (Ichimura et al, 2002). In a phylogenetic tree the conserved amino acid motif TxY, a phosphorylation site for MAPKKs, classifies the MPKs into two subtypes: a TEY subtype with a TEY motif and a TDY subtype with a TDY motif. MPKs with the TEY motif can be classified into subgroups A, B and C. Group D MAPKs are characterized by a TDY motif and an extended C-terminal region. Group A and B MPKs comprise evolutionary conserved common docking domains (CD-domains) in their C-terminal regions (Ichimura et al, 2002, Tanoue et al, 2000). This domain structure facilitates docking to MAPKKs, but also protein phosphatases and substrates. Two adjacent amino acids ( $D$ and $E$ ) are crucial for interaction with a cluster of basic amino acids ( $K$ und $R$ ) of MAPKKs in the sequence ([LH] [LHY]Dxx[DE]xx[DE]EPxC) conserved in this CD-domain (Tanoue et al, 2000). The group A members MPK3 and MPK6 are involved in various environmental stress and hormone responses (Nühse et al, 2000; Ichimura et al, 2000; Desikan et al, 2001; Yuasa et al, 2001). With the exception of MPK4 and MPK11, which are also involved in stress responses (Ichimura et al, 2000; Desikan et al, 2001, Teige, 2004, Bethke et al, 2011), little is yet known about the specific functions of most other group B and even less is known on group $C$ or group $D$ members, except that group $C$ members (MPK1, 2, 7 and 14) and at least one group D member (MPK8) are downstream of MKK3 which plays a role in pathogen and oxidative stress homeostasis (Döczi et al, 2007, Takahashi et al, 2011).

So far, there are only few reports concerning an involvement of MAPKs as part of the heat stress response. A heat-induced MAPK activation was shown in tomato and 
alfalfa, but their molecular roles have not been elucidated further (Link et al, 2002, Sangwan and Dhindsa, 2002). With the experiments presented here we reveal a potential involvement of phosphorylation events as part of the heat stress response in Arabidopsis and unravel a molecular mechanism how MPK6 negatively regulates the heat stress response. 


\section{Materials and Methods}

\section{Plant Materials and Growth Conditions}

The Arabidopsis thaliana ecotype Columbia (Col) was used as wild-type for developmental experiments as indicated. The mpk6 mutant was described earlier (Nakagami et al, 2006). Plants were grown on 0.5X MS medium (Sigma) under long day condition (16 hr light/8 hr dark) with a humidity level of $50 \%$ and $50 \mu \mathrm{E}$ cool white light. Stress treatments were performed according to Charng et al, 2007.

\section{Transient Expression Assays}

Transient expression assays were performed using Arabidopsis suspension cell culture and tobacco mesophyll protoplasts, respectively, as described (Forreiter et al. 1997; Nakagami et al, 2004; Lyck et al. 1997; Scharf et al. 1998a) with slight modifications. Protoplasts were isolated and transformed by PEG (polyethylene glycol) mediated transformation at room temperature $\left(25^{\circ} \mathrm{C}\right)$ under dark conditions. Plant expression vectors used are based on the pRT series of vectors (Töpfer et al. 1988; Döring et al. 2000). The expression vector for 3HA-HsfA2 and the reporter construct $P_{H s p 18-c: \text { : }}$ GUS was described by Schramm et al. (2006).

\section{Inhibitors}

To investigate the effect of phosphorylation and dephosphorylation on heat stress response, several broad-spectrum inhibitors were tested. All inhibitors were provided from Calbiochem, dissolved in DMSO as recommended and used at the following 
final concentrations: Staurosporin (Cat No. 569396) $10 \mu \mathrm{M}$, Cantharidin (Cat. No. 210155) $10 \mu \mathrm{M}$, Calyculin (Cat. No. 208851) $0.25 \mu \mathrm{M}$ and Okadaic acid (Cat. No. 459618) $2 \mu \mathrm{M}$.

\section{In-gel kinase assays}

C-terminal domains (CTD) of several Hsfs were cloned into the pDEST-15 vector (Invitrogen) and expressed in E. coli strain Rosetta (Novagen). Sequences of CTD-Hsfs proteins are described in supplemental table S1. GST-tagged Hsf proteins were purified using Glutathione sepharose 4B resin (Amersham) according the manufacturer recommendations. Cell extracts were prepared at different times after heat stress in extraction buffer $(25 \mathrm{mM}$ Tris $\pm \mathrm{HCl} p H$ 7.8, $15 \mathrm{mM}$ EGTA, $75 \mathrm{mM} \mathrm{NaCl}$, $1 \mathrm{mM}$ dithiothreitol (DTT), $10 \mathrm{mM} \mathrm{MgCl}, 1 \mathrm{mM} \mathrm{NaF}, 0.5 \mathrm{mM} \mathrm{NaVO}{ }_{3}, 15 \mathrm{mM}$ $\beta$-glycerophosphate, $15 \mathrm{mM}$ 4-nitrophenylphosphate, 0.1\% Tween-20, $0.5 \mathrm{mM}$ phenylmethylsulfonyl fluoride (PMSF), $5 \mathrm{mg} / \mathrm{ml}$ leupeptin, $5 \mathrm{mg} / \mathrm{ml}$ aprotinin). After centrifugation at $20000 \times \mathrm{xg}$ for $45 \mathrm{~min}$, the cleared supernatant was used. For in-gel protein kinase reactions, cell extracts containing $20 \mu \mathrm{g}$ of total protein per lane were separated by SDS-PAGE. Myelin basic protein (MBP; $0.5 \mathrm{mg} / \mathrm{ml}$ ) was used as a substrate polymerized in the polyacrylamide gel. After protein renaturation, the kinase reactions were performed in the gel as described (Usami et al, 1995). The gels were dried and analyzed by autoradiography.

\section{Immunocomplex kinase assays}


Protoplast extracts containing equal protein amounts $(100 \mu \mathrm{g})$ were subjected to a 2-h preincubation in the presence of $20 \mu \mathrm{l}$ of mixed protein A- and G-Sepharose beads (1:1). The supernatant was then immunoprecipitated with $5 \mu \mathrm{l}$ of anti-HA monoclonal antibody and $20 \mu \mathrm{l}$ of protein G-Sepharose beads overnight at $4^{\circ} \mathrm{C}$. The beads were washed three times with wash buffer (50 mM Tris, pH 7.4, $250 \mathrm{mM} \mathrm{NaCl}$, 5 mM EGTA, 5 mM EDTA, 0.1\% Tween 20) and once with kinase buffer (20 mM HEPES, $\mathrm{pH} 7.4,10 \mathrm{mM} \mathrm{MgCl}, 5 \mathrm{mM}$ EGTA, and $1 \mathrm{mM}$ dithiothreitol). Kinase reactions of the immunoprecipitated proteins were performed in $15 \mu \mathrm{l}$ of kinase buffer containing $5 \mu \mathrm{g}$ of MBP, $0.1 \mathrm{mM}$ ATP, and $2 \mu \mathrm{Ci}$ of $\left(\gamma^{-32} \mathrm{P}\right)$ ATP. The protein kinase reactions were performed at room temperature for $30 \mathrm{~min}$, and the reactions were stopped by adding 4x SDS loading buffer. The phosphorylation of MBP was analyzed by autoradiography after separation on 15\% SDS-PAGE.

\section{Immunoblotting}

Immunoblotting was performed with equal amounts of protein separated by $10 \%$ SDS-PAGE and transferred to PVDF membranes (Millipore) by electroblotting. Membranes were probed with A-purified M23 (raised against MPK6), or with either anti-HA monoclonal antibody or with anti-Myc polyclonal antibody (A-14, Santa Cruz Biotechnology) or with anti-GFP antibody (sigma). Membranes were developed by enhanced chemiluminescence as recommended by the manufacturer (Gene Image, Amersham Biosciences).

\section{Confocal imaging Using Arabidopsis Mesophyll Protoplasts.}


HsfA2 WT and mutated sequences were PCR amplified using the pRTHsfA2 vector (Doring et al, 2000) as a template. Primers used for PCRs are listed in supplemental table S2. For site directed mutagenesis a first PCR using the following pairs were generated: Hsfa2NS-GW2-CterF/Hsfa2-249A-R

(PCR1); Hsfa2NS-GW2-CterF/Hsfa2-T249D-R (PCR2); Hsfa2NS-GW2-R/Hsfa2-T249A-F (PCR3) and Hsfa2NS-GW2-R/Hsfa2-T249D-F (PCR4). PCR1 and PCR3 or PCR2 and PCR4 products were diluted and mixed together and then re-amplified with the Hsfa2NS-GW2-CterF/Hsfa2NS-GW2-R primer pairs to generate HsfA2-T249A and HsfA2-T249D mutants. pRTHsfA2 was also amplified with Hsfa2NS-GW2-CterF/Hsfa2NS-GW2-R to generate the HsfA2-WT version. The three PCR products were then introduced in pDNR207 (Invitrogen) trough a classical Gateway-BP reaction. After sequence verification HsfA2 constructs were introduced in p2GWF7 (Karimi et al, 2007) by a Gateway-LR reaction (Invitrogen) to give HsfA2-WT-GFP, HsfA2-T249A-GFP, and HsfA2-T249D-GFP plasmids. MPK7 construct was amplified with MPK7NS-GW2-CterF/ MPK7NS-GW2-R to generate MPK7-GFP plasmid and was used as a control for immunobloting (see below).Transient expression assays were performed using Arabidopsis mesophyll protoplasts isolated and transformed as described (Yoo et al. 2007). Confocal imaging were performed with a Leica TCS-SP2 confocal microscope and analysed with the Leica confocal software (LCS). Autofluorescence and overlay pictures are described in supplemental Figure S1.

\section{Accession Numbers}


Sequence data from this article can be found in the GenBank/EMBL data libraries under accession numbers: MPK6 (At2g43790), HsfA2 (At2g26150).

\section{Mass spectrometry}

Coomassie blue stained phosphorylated and non-phosphorylated HsfA2 protein bands were excised from the SDS-PAGE. Ion trap mass spectrometry was performed as according to the user manual and as described in de la Fuente van Bentem et al, (2006). 


\section{Results and discussion}

\section{MPK6 is activated by heat stress}

To get insights into the protein kinases regulated in response to heat stress, we performed in-gel kinase assays of protein extracts from Arabidopsis leaves before and after exposure to heat stress (Fig. 1). Detached leaves were incubated in pre-heated $\left(37^{\circ} \mathrm{C}\right)$ liquid medium and then placed at $37^{\circ} \mathrm{C}$ for $1 \mathrm{~h}$. As shown by in-gel kinase assays, several MBP-phosphorylating protein kinases in the range between 40-72 kDa become activated by heat stress (Fig. 1A). The strongest activity corresponds to a protein kinase with an approximative molecular mass of $48 \mathrm{kDa}$ that displayed a maximum activation within 2 min of heat stress before returning to lower levels by $20 \mathrm{~min}$. The transient activation of the $48 \mathrm{kDa}$ protein kinase that is able to phosphorylate MBP in Arabidopsis resembled to the class of mitogen-activated protein kinases that was previously reported in tomato and alfafa (Link et al, 2002; Sangwan and Dhindsa, 2002). We confirmed this hypothesis by immunocomplex kinase assays with a specific antibody against Arabidopsis MPK6 (Fig. 1B). The corresponding immunoblotting experiments indicated that the observed heat-induced kinase activity was not due to changes in MPK6 protein amounts (Fig. 1B). These results indicate that in Arabidopsis, MPK6 might be the major heat stress transducer in plant cells and the activation of this MAPK is a highly conserved process in plants. These results confirm also the HS induced MPK6 activity detected in Arabidopsis leaves obtain by Li et al. (2012).

With in-gel kinase assays we could observe in samples from heat-stressed leaves one dominant heat-activated protein kinase of approximately $48 \mathrm{kDa}$ (Fig. 1A) similar 
to that reported by Link et al. (2002) for tomato. MBP phosphorylation has been also detected to a lower extent for proteins in the range around $60 \mathrm{kDa}$ proteins (Fig. 1A) and these kinases might also participate in the heat stress response. However, by immunocomplex assays with specific antibodies, we identified MPK6 as the most prominent heat stress-induced protein kinase in whole cell extracts (Fig. 1B). These results show that heat stress activation of MAPKs is also a highly conserved process in plants and add another factor to the list of activating conditions of MPK6, which was so far reported to be activated upon cold, salt, oxidative, hypoosmotic, ozone and genotoxic stress (Droillard et al, 2004; Lee and Ellis, 2007; Teige et al, 2004; Ulm et al, 2002; Yuasa et al, 2001), plant defence to biotic stress (Brader et al, 2007, Menke et al, 2004; Schweighofer et al, 2007) as well as jasmonate and ethylene signalling (Ouaked et al, 2003; Takahashi et al, 2007; Schweighofer et al, 2007).

\section{Phosphorylation of heat stress transcription factors by MPK6}

In order to address the possibility that MPK6 could affect the heat stress response by direct phosphorylation of Hsfs as the regulators of the heat stress response, we performed in vitro kinase assays using active MPK6 on 16 recombinant GST-Hsf fusion proteins, representing all Hsf protein subgroups. To clarify the specificity of the enzymatic interactions, the GST-Hsf fusions carried only the divergent C-terminal regulatory domains but not the highly conserved $\mathrm{N}$-terminal DNA binding domains (see Kotak et al, 2004). As shown in Fig. 2A, MPK6 was able to phosphorylate several GST-Hsfs in vitro, but GST-HsfA2 appeared to be most strongly phosphorylated. In order to validate that the phosphorylation reactions towards the 
Hsf domains were specific, in vitro kinase assays were also performed with GST and MBP as negative and positive controls, respectively. Whereas MPK6 strongly phosphorylated MBP and GST-HsfA2, no phosphorylation was detected for GST (Fig. 2B).

Because transcription factors are common targets of MAPKs, we undertook a systematic in vitro screen for MPK6 targets among the 21 Arabidopsis Hsfs. Out of 16 candidates, representing all Arabidopsis Hsf subfamilies, MPK6 phosphorylated several members of different Hsf subclasses, but showed strong phosphorylation of HsfA2 (Fig. 2A). MPK6 was also shown to phosphorylate full length HsfA2 (Fig. 2B). Recently, putative targets of MPK3 and 6 have been described by Sörensson et al (2012). HsfA4e appear to contain the PPSPR motif and might be another target of MPK6.

\section{In vivo complex formation between MPK6 and HsfA2}

The in vitro kinase assays (Fig. 2B) indicated that MPK6 is able to phosphorylate HsfA2. To corroborate that HsfA2 is a specific target of MPK6, we also tested whether MPK6 can directly interact with HsfA2 in vivo. For this purpose, we transiently expressed MPK6 and full-length wild type HsfA2 in Arabidopsis cells under the constitutive 35S Cauliflower Mosaic virus (CaMV) promoter (Fig. 3). MPK6 and HsfA2 were expressed as tagged proteins with either the Myc-epitopes or the Hemagglutinin-(HA), respectively, to allow their immunoprecipitation and immunodetection. Protoplasts co-expressing MPK6-Myc and 3HA-HsfA2 were then incubated at $37^{\circ} \mathrm{C}$ for 5 min before protein extraction. Using an anti-Myc antibody, 
MPK6-Myc was immunoprecipitated, and the presence of 3HA-HsfA2 in the complex was assayed by protein gel blot analysis using anti-HA antibody (Fig. 3A). HsfA2 was found to interact strongly with MPK6 at 5 min after heat stress treatment.

Although both 3HA-HsfA2 and MPK6-Myc were produced under the 35S CaMV promoter, we also tested whether the protein amounts changed during the course of the experiment. Anti-Myc immunoblotting showed that the protein amounts of MPK6-Myc and 3HA-HsfA2 did not change during the heat treatment (Fig. 3B). Overall, these experiments indicate that HsfA2 is a target of MPK6.

\section{MPK6 phosphorylates HsfA2 on threonine 249}

To determine the MPK6 phosphorylation sites in HsfA2, we performed an in vitro kinase assay by incubating the recombinant GST-HsfA2 protein in the presence of cold ATP with or without active MPK6. The reaction products were separated by SDS-PAGE and excised after Coomassie blue staining. Upon in-gel alkylation-tryptic digestion, each digested sample was subjected to mass spectrometric analysis. No phosphorylated residue was detected in the nonphosphorylated sample, whereas a single phosphopeptide with the sequence 245RLTSTPSLGTMEENLLHDQEFDR268 was found for HsfA2 that was incubated with active MPK6 (Fig. 4A). A single phosphorylation site corresponded to the 247TST249 motif, but could not be identified to a specific residue within this sequence with certainty. We next mutated the 247TST249 in HsfA2 to 247AAA249 and expressed the mutant protein as recombinant GST fusion protein. When tested with active MPK6, the mutant HsfA2 247AAA249 protein could not be phosphorylated any more (unpublished results). 
Since MAP kinases absolutely require a proline residue in the +1 position following the serine/threonine phosphorylation site, we then only mutated T249 to alanine (T249A). As shown in Fig. 4B, MPK6 phosphorylated wild type GST-HsfA2 but not GST-HsfA2 T249A, indicating that T249 is the amino acid residue that is phosphorylated by MPK6. However, because of the presence of additional putative phosphorylation sites within the HsfA2 protein sequence we cannot rule out that other sites might be targeted by MPK6 or other kinases and play a role in its regulation.

\section{T249 phosphorylation regulates heat stress-induced nuclear accumulation of}

\section{HsfA2}

T249 lies in close proximity to the nuclear localization sequence (NLS) of HsfA2 (Figure 4A), suggesting that phosphorylation of T249 could affect the localization of HsfA2. To analyse the possible consequences of phosphorylation of T249, we mutated T249 not only to alanine T249A to disable phosphorylation but also to glutamic acid T249D to mimic a phosphorylated status. Wild type HsfA2 (HsfA2-WT) and mutant T249A (HsfA2-T249A) or T249D (HsfA2-T249D) were then fused with GFP and expressed in Col-0 protoplasts under the constitutive 35S CaMV promoter. At ambient room temperature of $22^{\circ} \mathrm{C}$ (RT), wild type HsfA2-WT and mutant HsfA2-T249A and HsfA2-T249D proteins showed similar cytoplasmic and nuclear localization (Figure 5A, Col-0, RT). Upon heat stress, wild type and HsfA2-T249D accumulated in the nuclear compartment, whereas HsfA2-T249A was still distributed between cytoplasm and nucleus as in untreated cells (Figure 5A, Col-0, HS). 
Threonine 249 that lies close to the nuclear localization signal of HsfA2, suggests that phosphorylation of this site might affect the intracellular localization of HsfA2. Localization studies performed in this work confirmed this hypothesis proving that T249 phosphorylation regulates the nuclear localization of HsfA2 upon heat stress. However we cannot discriminate whether nuclear localization of HsfA2 upon heat stress is a result of a cytosolic instability or a basic shuttling between the cytosol and the nucleus.

\section{MPK6 regulates heat stress-induced nuclear accumulation of HsfA2}

To clarify whether MPK6 is responsible for the heat stress-induced nuclear accumulation, we then tested the behaviour of the HsfA2-GFP construct in protoplasts derived from mpk6 knock out plants (Figure 5B). Therefore, we expressed the wild type HsfA2-GFP construct in protoplasts prepared from mpk6 knock out plants at ambient room temperature of $22^{\circ} \mathrm{C}(\mathrm{RT})$ or $37^{\circ} \mathrm{C}(\mathrm{HS})$. Under ambient conditions or heat stress conditions, HsfA2-GFP showed a similar distribution between nucleus and cytoplasm (Figure 5B). Under heat stress conditions, HsfA2-GFP showed nuclear accumulation only in Col-0 derivative protoplasts, indicating that MPK6 is the responsible factor that induces nuclear shuttling of HsfA2. S320 Phosphorylation of the human Hsf1 by a Protein Kinase plays a significant role in it nuclear localization (Murshid et al, 2010). Results presented in our work confirm that phosphorylation events are conserved mechanisms among organisms and kingdoms and regulate important biological responses to stress. 


\section{Phosphorylation-dependent regulation of HsfA2 protein levels upon heat stress}

Because HsfA2 phosphorylation can affect HsfA2 function we used protein kinase and phosphatase inhibitors in Arabidopsis mesophyll protoplasts. Upon application of the broad-spectrum protein kinase inhibitor staurosporine, or the protein phosphatase inhibitors cantharidin, calyculin and okadaic acid, the expression levels of endogenous HsfA2 or one of its targets, the heat stress-induced protein Hsp18.1-CI (Schramm et al, 2006) was determined in Arabidopsis cells (Fig. 6A). After application of the inhibitors, the cells were split into two aliquots and one aliquot was heat stressed for $3 \mathrm{hrs}$ at $37^{\circ} \mathrm{C}$ whereas the other aliquot was kept at $22^{\circ} \mathrm{C}$. Applying cantharidin had no marked effects on HsfA2 protein level in heat stressed cells (Fig. 6A). However, application of the kinase inhibitor staurosporin as well as the phosphatase inhibitor okadaic acid resulted in dramatically reduced levels of HsfA2 protein and consequently blocked almost completely the expression of sHsp-CI (Fig. 6A). These experiments indicated that phosphorylation and dephosphorylation events can influence the heat stress response of cells. Yet, it was not clear if HsfA2 and its downstream target Hsp18-CI were affected at the gene expression or protein levels, or if the observed effects were due to indirect effects of the inhibitors. Therefore, the inhibitors were also investigated in cells that constitutively express 3HA-HsfA2 under the 35S CaMV promoter but in the absence of heat stress. Protein extracts of the differently treated cells were probed with HA antibody in Western blots. DMSO as the solvent of the inhibitors alone had no marked effect on 3HA-HsfA2 levels, but both staurosporine as well as the three phosphatase inhibitors resulted in strongly 
reduced 3HA-HsfA2 protein levels and GUS accumulation mediated by the Hsp18.1-CI promoter (Fig. 6B and 6C). The changes in 3HA-HsfA2 protein levels were not due to a general toxic effect on the cells as protein amounts of Rubisco did not change significantly (Fig. 6B). These results show that phosphorylation-dependent mechanisms regulate HsfA2 protein amounts in vivo.

Using broad-spectrum protein kinase and phosphatase inhibitors resulted in a strong reduction in HsfA2 protein levels in Arabidopsis cells upon heat stress activation (Fig. 6). Since HsfA2 is regulated at both, the transcriptional and post-translational level (Busch et al, 2005; Schramm et al, 2008; Cohen-Peer et al. 2010 and Ikeda et al, 2011), we also tried to uncouple these two levels of regulation by testing whether these effects are also observed when HsfA2 was permanently expressed under the constitutive 35S CaMV promoter. Under these conditions, we observed that inhibition of phosphorylation still reduced HsfA2 protein abundance upon heat stress except for Cantharidin for which no marked effect has been observed in a native promoter condition (Fig. 6). These data suggest that these drugs might target different protein phosphatase complexes associated with plant heat stress signalling.

\section{Phosphorylation-dependent HsfA2 protein abundance regulation depends on other protein kinases than MPK6}

Our work so far revealed that HsfA2 is a specific substrate of MPK6 (Fig. 2) that interacts with MPK6 in a heat stress-dependent manner (Fig. 3A). We also obtained evidence that HsfA2 protein abundance is regulated by phosphorylation (Fig. 5). To test this hypothesis, we performed Western blots of 3HA-HsfA2 upon co-expression 
of MPK6-Myc alone, or together with a constitutively active form of an MPK-activating MAPKK MKK2 (MKK2 ${ }^{\mathrm{GOF}}$ ), in Arabidopsis cells under the constitutive $35 \mathrm{~S}$ CaMV promoter (Fig. 7). Under these conditions, MPK6 is directly activated by MKK2 ${ }^{\text {GOF }}$ and no heat stress is necessary for its activation. To differentiate between activated and non-activated MPK6, HsfA2 and MPK6 were also co-expressed with the wild type form of MKK2. When HsfA2 was co-expressed with MPK6 or together with MKK2 or MKK2 ${ }^{\mathrm{GOF}}$, HsfA2 levels were not affected when compared to expression of HsfA2 alone (Fig. 7). As a control, we also co-expressed HsfA2 with the MKK2 wild type and GOF version without MPK6. Under both conditions, HsfA2 protein levels did not show any reduction when compared to HsfA2 expression alone. To confirm that MPK6 was not involved in HsfA2 stability, we compared the level of HsfA2-GFP protein in Col-0 versus mpk6 protoplasts under heat stress conditions (Supplemental Figure S2). Under these conditions, degradation of HsfA2 wasn't affected in the absence of MPK6. These data indicate that activated MPK6 does not regulate HsfA2 protein abundance. We conclude that other yet unidentified sites and most likely other protein kinases regulate HsfA2 protein stability.

\section{Conclusion}

The heat stress response is a complex mechanism to protect plants against cell damage through protein degradation and aggregation during high temperatures. In mammals, the components of this molecular regulation machinery are well studied, while for plants only little is known. In yeast and mammals, phosphorylation was found to regulate the activity of Hsfs as part of the heat stress response (Holmberg et 
al, 2002; Sorger and Pelham, 1988, Pirkkala et al, 2001). One major class of kinases are the mitogen-activated protein kinases (MAPKs). In the stress response of Arabidopsis they were found to be involved in various signal transduction pathways, but up to now, a role of MAPKs in the Arabidopsis heat stress response was not defined. The present study demonstrates that MPK6 in Arabidopsis is activated by heat stress and targets the transcription factor HsfA2. This work confirms also the results obtained by Li et al, (2012) where they nicely demonstrated that implication of one Vacuolar processing Enzyme ( $\gamma \mathrm{VPE})$ in HS induced cell death was MPK6 dependent. We also confirmed the mpk6 tolerance to heat shock (supplemental Figure S3). Li et al, demonstrated that $\gamma \mathrm{VPE}$ expression and activity was dependent on MPK6 function, however, whether YVPE direct phosphorylation might be associated with it activity could be investigated in the future. Also, rVPE encoding gene contain a highly conserved palindromic HSE in it promoter ((-605 AGAAAAAGATTCT -593), Bienz and Pelham, 1987; Nover, 1991 and Schram et al, 2006)). It would be interesting to investigate in further experiments whether HsfA2 could be a direct transcriptional regulator of the $\gamma \mathrm{VPE}$ gene.

Our data show that MPK6 interacts with HsfA2 in vivo upon heat stress. Moreover, we could show that MPK6 phosphorylates T249 of HsfA2 and thereby contributes to regulate the intracellular localization of HsfA2. Protein kinase and phosphatase studies indicated that HsfA2 protein stability is regulated in a phosphorylation-dependent manner. However, our studies showed that this mechanism is independent of MPK6. These data are compatible with the fact that expression, abundance and activity of HsfA2 are subject to multiple regulatory 
mechanisms. First, it was recently shown that Arabidopsis HsfB1 and HsfB2b negatively regulate the expression of several heat-inducible Hsfs, including HsfA2, and thereby several heat shock proteins (Ikeda et al, 2011). In addition, HsfA1d and HsfA1e were identified to positively regulate HsfA2 gene expression by interacting with heat stress elements in the $5^{\prime}$-flanking region of the HsfA2 promoter (Nishizawa-Yokoi et al, 2011). It was also shown that the proteasome inhibitor MG132 affects expression of HsfA2 and its downstream targets (Nishizawa-Yokoi et al, 2011). Although the authors did not analyze whether MG132 also affects HsfA2 protein stability, there is evidence that the activity of the HsfA2 protein is regulated by post-translational mechanisms. Cohen-Peer et al. (2010) showed that SUMOylation of HsfA2 occurs in vitro and in vivo and regulates the potential of HsfA2 to activate downstream targets. Taken together, it is evident that HsfA2 is a key transcriptional regulator of the heat stress response that is subjected to multi-level regulation itself and that MPK6 only contributes to a certain degree to the full complexity of its regulation.

\section{Acknowledgments}

We thank Gisela Englich for her excellent technical help. This work was supported by grants from the Austrian Science Foundation, the Deutsche Forschungsgemeinschaft (AFGN grant KO2888-1-1/2) and the French National Agency ANR. 


\section{Figure Legends}

Figure 1. Heat stress-induced MPK6 activation in Arabidopsis leaves. After pre-incubation in liquid medium at $24^{\circ} \mathrm{C}$ for $2 \mathrm{~h}$, detached Arabidopsis leaves were transferred to pre-heated $\left(37^{\circ} \mathrm{C}\right)$ liquid medium and then placed at $37^{\circ} \mathrm{C}$ for up to 60 min (hs: heat stress). Total protein extracts were used to perform in-gel protein kinase assays (A), and immunocomplex kinase assays with protein gel blot analysis (B). For the in-gel protein kinase assays, $20 \mu \mathrm{g}$ of total proteins per lane were separated by SDS-PAGE. MBP $(0.5 \mathrm{mg} / \mathrm{ml})$ was used as a substrate polymerized in the polyacrylamide gel. MPK6 activity was determined at different times by immunocomplex kinase assay using $5 \mu \mathrm{g}$ of protein A-purified MPK6-specific peptide M23 antibody. To monitor the protein levels, equal aliquots of the same extracts were analyzed by protein gel blot analysis using $\alpha$ MPK 6 antibodies.

Figure 2. In vitro phosphorylation of heat stress transcription factors by MPK6. (A) C-terminal domains (CTD) of several Hsfs were fused to GST. Using an HA-antibody, MPK6-HA was immunoprecipitated from Arabidopsis mesophyll protoplasts treated with $10 \mathrm{mM} \mathrm{H}_{2} \mathrm{O}_{2}$ for 10 minutes to activate MPK6 (Rentel et al, 2004). MPK6 was incubated with the purified GST-Hsfs for in vitro kinase assays with

${ }^{32} \mathrm{P}-\gamma$-ATP. The samples were separated on SDS-PAGE before Coomassie blue staining and autoradiography. M: molecular weight marker. (B) Similar assays as performed in (A) using in addition to GST-HsfA2 MBP and GST as controls. GST fusion proteins of HsfA2 is indicated by an arrow. 
Figure 3. In vivo complex formation of MPK6 with HsfA2. 3HA-HsfA2 was coexpressed with MPK6-Myc in Arabidopsis protoplasts. 16h after transformation, protoplast samples were harvested before (0) or after incubation in a water bath at $37^{\circ} \mathrm{C}$ for 5 min (5). (A) Total protein extracts were immunoprecipitated (IP) with $\alpha$ Myc antibody, and the immunoprecipitates were immunoblotted (Blot) for 3HA-HsfA2 with $\alpha \mathrm{HA}$ antibody. (B) To monitor the protein levels, part of the same extracts were analyzed by protein gel blot analysis using $\alpha \mathrm{HA}$ and $\alpha \mathrm{Myc}$ antibodies.

Figure 4. MPK6 phosphorylate HsfA2 on T249. (A) Block Diagram of HsfA2 and the single phosphorylated T249 site identified by mass spectrometry. The functional domains involved in DNA-binding (DBD), oligomerization (HR-A/B), nuclear import (NLS) and nuclear export (NES) as well as its transcription activation potential (AHA) are indicated (Nover et al, 2001; Schramm et al, 2006). The mutated T249 motif is shown in the lower panel. (B) Mutation of T249 (HsfA2-T249A) abrogates phosphorylation of GST-HsfA2 by MPK6. GST fusion proteins of HsfA2 and HsfA2-T249A are indicated by an arrow, whereby GST as control is indicated by an asterisk.

Figure 5. Analysis of the subcellular distribution of HsfA2 during a heat stress. (A) HsfA2-WT-GFP, HsfA2-T249A-GFP, and HsfA2-T249D-GFP constructs were used to transform Col-0 Arabidopsis mesophyll protoplasts. Preceding confocal analysis, protoplasts were incubated for $4 \mathrm{~h}$ to $22^{\circ} \mathrm{C}$ (RT) or $37^{\circ} \mathrm{C}(\mathrm{HS})$. (B) 
HsfA2-WT-GFP construct was used to transform mpk6 Arabidopsis mesophyll protoplasts and same experimental conditions were applied as in (A). Images are confocal scanning laser micrographs of protoplasts showing specific GFP fluorescence. Excitation wavelength was $495-530 \mathrm{~nm}$ for GFP and $636-676 \mathrm{~nm}$ for autofluorescence. Scale bar is $20 \mu \mathrm{m}$. Subcellular localization analysis was carried out at least three times with similar results.

Figure 6. Protein kinase and phosphatase inhibitors affect the expression of heat stress-induced proteins. (A) Arabidopsis mesophyll protoplasts were treated with the inhibitors indicated (Sta: Staurosporin; Can: Cantharidin; Cal: Calyculin and Oka: okadaic acid) or mock treated with 1\% DMSO (DMSO). After 30 min samples were split and kept either at RT as controls (rt) or heat stressed for three hours at $36^{\circ} \mathrm{C}$ (hs). After another 60 min samples were harvested, proteins extracted and analyzed by immunoblot analysis with the antibodies indicated (Schramm et al, 2006). (B) The protein stability potential of $3 \mathrm{HA}-\mathrm{HsfA} 2$ was tested in tobacco protoplasts in the presence of protein kinase and phosphatase inhibitors and (C) a reporter construct contained $1 \mathrm{~kb}$ of the Hsp18.1-Cl promoter fused to GUS. The resulting GUS activities (relative fluorescence units, RFU) and protein stability are presented after co-transformation with the 35S::3HA-HsfA2 constructs (+) and inhibitors as in (A). Error bars correspond to the standard deviation of three independent replicates. 
Figure 7. MPK6 does not regulate HsfA2 protein stability. 3HA-HsfA2 protein abundance is evaluated by immunoblot analysis (2 to 5 ) from protoplast extracts co-expressing MPK6 (3 to 5) or an empty vector (1-2). Co-expression of active MKK $2^{\mathrm{GOF}}$ is used to activate MPK6 in protoplasts. Co-expression of native form of MKK2 was used as control. MKK2 amounts are estimated by immunoblot analysis.

\section{References}

Baniwal SK, Bharti K, Chan KY, Fauth M, Ganguli A, Kotak S, Mishra SK, Nover L, Port M, Scharf KD, Tripp J, Weber C, Zielinski D, von Koskull-Döring P. (2004). Heat stress response in plants: a complex game with chaperones and more than twenty heat stress transcription factors. J Biosci 29:471

Baniwal SK, Chan KY, Scharf KD, Nover L. (2007). Role of heat stress transcription factor HsfA5 as specific repressor of HsfA4. J Biol Chem 282:3605

Bethke G, Pecher P, Eschen-Lippold L, Tsuda K, Katagiri F, Glazebrook J, Scheel D, Lee J. Activation of the Arabidopsis thaliana mitogen-activated protein kinase MPK11 by the flagellin-derived elicitor peptide, flg22. Mol Plant Microbe Interact 25:471

Bienz M. Pelham HRB. 1987. Mechanisms of heat-shock gene activation in higher eukaryotes. Adv. Genet 24: 31

Brader G, Djamei A, Teige M, Palva ET, Hirt, H. (2007). The MAP kinase kinase MKK2 affects disease resistance in Arabidopsis. Mol Plant Microbe Interact 20:589 
Busch W, Wunderlich M, Schoffl F. (2005). Identification of novel heat shock factor-dependent genes and biochemical pathways in Arabidopsis thaliana. Plant $\mathrm{J}$ $41: 1$

Charng YY, Liu HC, Liu NY, Chi WT, Wang CN, Chang SH, Wang TT. (2007). A heat-inducible transcription factor, HsfA2, is required for extension of acquired thermotolerance in Arabidopsis. Plant Physiol 143:251

Chu B, Soncin F, Price BD, Stevenson MA, Calderwood SK. (1996). Sequential phosphorylation by mitogen-activated protein kinase and glycogen synthase kinase 3 represses transcriptional activation by heat shock factor-1. J Biol Chem 271:30847 Cohen-Peer R, Schuster S, Meiri D, Breiman A, Avni, A. (2010). Sumoylation of Arabidopsis heat shock factor A2 (HsfA2) modifies its activity during acquired thermotholerance. Plant Mol Biol 74:33

Czarnecka-Verner E, Pan S, Salem T, Gurley W.B. (2004). Plant class B HSFs inhibit transcription and exhibit affinity for TFIIB and TBP. Plant Mol Biol 56:57

Czarnecka-Verner E, Yuan CX, Scharf KD, Englich G, Gurley WB. (2000). Plants contain a novel multi-member class of heat shock factors without transcriptional activator potential. Plant Mol Biol 43:459

Davletova S, Schlauch K, Coutu J, Mittler R. (2005). The zinc-finger protein Zat12 plays a central role in reactive oxygen and abiotic stress signaling in Arabidopsis. Plant Physiol 139:847

de la Fuente van Bentem S, Anrather D, Roitinger E, Djamei A, Hufnagl T, Barta A, Csaszar E, Dohnal I, Lecourieux D, Hirt H. (2006). Phosphoproteomics reveals 
extensive in vivo phosphorylation of Arabidopsis proteins involved in RNA metabolism. Nucleic Acids Res 34:3267

Desikan R, Hancock JT, Ichimura K, Shinozaki K, Neill SJ. (2001). Harpin induces activation of the Arabidopsis mitogen-activated protein kinases AtMPK4 and AtMPK6. Plant Physiol 126:1579

Doczi R, Brader G, Pettko-Szandtner A, Rajh I, Djamei A, Pitzschke A, Teige M, Hirt H. (2007). The Arabidopsis mitogen-activated protein kinase kinase MKK3 is upstream of group C mitogen-activated protein kinases and participates in pathogen signaling. Plant Cell 19:3266

Doring P, Treuter E, Kistner C, Lyck R, Chen A, Nover, L. (2000). The role of AHA motifs in the activator function of tomato heat stress transcription factors HsfA1 and HsfA2. Plant Cell 12:265

Droillard MJ, Boudsocq M, Barbier-Brygoo H, Lauriere, C. (2004). Involvement of MPK4 in osmotic stress response pathways in cell suspensions and plantlets of Arabidopsis thaliana: activation by hypoosmolarity and negative role in hyperosmolarity tolerance. FEBS Lett $574: 42$

Forreiter C, Kirschner M, Nover L. (1997). Stable transformation of an Arabidopsis cell suspension culture with firefly luciferase providing a cellular system for analysis of chaperone activity in vivo. Plant Cell 9:2171

Hartl FU, Hayer-Hartl M. (2002). Molecular chaperones in the cytosol: from nascent chain to folded protein. Science 295:1852 
Hashikawa N, Sakurai H. (2004). Phosphorylation of the yeast heat shock transcription factor is implicated in gene-specific activation dependent on the architecture of the heat shock element. Mol Cell Biol 24:3648

Haslbeck M. (2002). sHsps and their role in the chaperone network. Cell Mol Life Sci $59: 1649$

Hoj A, Jakobsen BK. (1994). A short element required for turning off heat shock transcription factor: evidence that phosphorylation enhances deactivation. Embo $\mathrm{J}$ $13: 2617$

Holmberg $\mathrm{Cl}$, Hietakangas V, Mikhailov A, Rantanen JO, Kallio M, Meinander A, Hellman J, Morrice N, MacKintosh C, Morimoto RI, Eriksson JE, Sistonen L. (2001). Phosphorylation of serine 230 promotes inducible transcriptional activity of heat shock factor 1. Embo J 20:3800

Holmberg Cl, Tran SE, Eriksson JE, Sistonen, L. (2002). Multisite phosphorylation provides sophisticated regulation of transcription factors. Trends Biochem Sci 27:619 Hubel A, Lee JH, Wu C, Schoffl F. (1995). Arabidopsis heat shock factor is constitutively active in Drosophila and human cells. Mol Gen Genet 248:136

Hubel A, Schoffl F. (1994). Arabidopsis heat shock factor: isolation and characterization of the gene and the recombinant protein. Plant Mol Biol 26:353

Ichimura, K. (2002). Mitogen-activated protein kinase cascades in plants: a new nomenclature. Trends Plant Sci 7:301

Ichimura K, Mizoguchi T, Yoshida R, Yuasa T, Shinozaki K. (2000). Various abiotic stresses rapidly activate Arabidopsis MAP kinases ATMPK4 and ATMPK6. Plant $\mathrm{J}$ 24:655 
Ikeda M, Mitsuda N, Ohme-Takagi M. (2011). Arabidopsis HsfB1 and HsfB2b act as repressors of the expression of heat-inducible Hsfs but positively regulate the acquired thermotolerance. Plant Physiol 157:1243

Kim BH, Schoffl F. (2002). Interaction between Arabidopsis heat shock transcription factor 1 and $70 \mathrm{kDa}$ heat shock proteins. J Exp Bot 53:371

Kline MP, Morimoto RI. (1997). Repression of the heat shock factor 1 transcriptional activation domain is modulated by constitutive phosphorylation. Mol Cell Biol 17:2107 Knauf U, Newton EM, Kyriakis J, Kingston RE. (1996). Repression of human heat shock factor 1 activity at control temperature by phosphorylation. Genes Dev 10:2782 Kotak S, Larkindale J, Lee U, von Koskull-Doring P, Vierling E, Scharf, KD. (2007a). Complexity of the heat stress response in plants. Curr Opin Plant Biol 10:310 Kotak S, Port M, Ganguli A, Bicker F, von Koskull-Doring P. (2004). Characterization of C-terminal domains of Arabidopsis heat stress transcription factors (Hsfs) and identification of a new signature combination of plant class A Hsfs with AHA and NES motifs essential for activator function and intracellular localization. Plant J 39:98

Kotak S, Vierling E, Baumlein H, von Koskull-Doring P. (2007b). A novel transcriptional cascade regulating expression of heat stress proteins during seed development of Arabidopsis. Plant Cell 19:182

Lee JS, Ellis B.E. (2007). Arabidopsis MAPK phosphatase 2 (MKP2) positively regulates oxidative stress tolerance and inactivates the MPK3 and MPK6 MAPKs. $J$ Biol Chem 282:25020 
Li C Chen Q, Gao X, Qi B, Chen N, Xu S, Chen J, Wang X. (2005). AtHsfA2 modulates expression of stress responsive genes and enhances tolerance to heat and oxidative stress in Arabidopsis. Sci China C Life Sci. 48:540

Link V, Sinha AK, Vashista P, Hofmann MG, Proels RK, Ehness R, Roitsch T. (2002). A heat-activated MAP kinase in tomato: a possible regulator of the heat stress response. FEBS Lett 531:179

Lohmann C, Eggers-Schumacher G, Wunderlich M, Schoffl F. (2004). Two different heat shock transcription factors regulate immediate early expression of stress genes in Arabidopsis. Mol Genet Genomics 271:11-21.

Lyck R, Harmening U, Hohfeld I, Treuter E, Scharf K.D, Nover L. (1997). Intracellular distribution and identification of the nuclear localization signals of two plant heat-stress transcription factors. Planta 202:117

Menke FL, van Pelt JA, Pieterse CM, Klessig DF. (2004). Silencing of the mitogen-activated protein kinase MPK6 compromises disease resistance in Arabidopsis. Plant Cell 16:897

Meszaros T, Helfer A, Hatzimasoura E, Magyar Z, Serazetdinova L, Rios G, Bardoczy V, Teige M, Koncz C, Peck S, Bogre L. (2006). The Arabidopsis MAP kinase kinase MKK1 participates in defence responses to the bacterial elicitor flagellin. Plant $\mathrm{J}$ $48: 485$

Miller G, Mittler R. (2006). Could heat shock transcription factors function as hydrogen peroxide sensors in plants? Ann Bot 98:279 
Morimoto RI. (1998). Regulation of the heat shock transcriptional response: cross talk between a family of heat shock factors, molecular chaperones, and negative regulators. Genes Dev 12:3788

Murshid A, Chou SD, Prince T, Zhang Y, Bharti A, Calderwood SK. (2010). Protein kinase A binds and activates heat shock factor 1. PLoS One 9:e13830

Nakagami H, Kiegerl S, Hirt H. (2004). OMTK1, a novel MAPKKK, channels oxidative stress signaling through direct MAPK interaction. J Biol Chem 279:26959

Nakagami H, Soukupova H, Schikora A, Zarsky V, Hirt, H. (2006). A Mitogen-activated protein kinase kinase kinase mediates reactive oxygen species homeostasis in Arabidopsis. J Biol Chem 281:38697

Nakamoto H, Vigh, L. (2007). The small heat shock proteins and their clients. Cell Mol Life Sci 64:294

Nishizawa A, Yabuta Y, Yoshida E, Maruta T, Yoshimura K, Shigeoka, S. (2006). Arabidopsis heat shock transcription factor A2 as a key regulator in response to several types of environmental stress. Plant J 48:535

Nishizawa-Yokoi A, Tainaka H, Yoshida E, Tamoi M, Yabuta Y, Shigeoka, S. (2010). The 26S proteasome function and Hsp90 activity involved in the regulation of HsfA2 expression in response to oxidative stress. Plant Cell Physiol 51:486

Nover L. (Ed.) 1991. Heat Shock Response. CRC Press, Boca Raton.

Nover L, Bharti K, Doring P, Mishra SK, Ganguli A, Scharf KD. (2001). Arabidopsis and the heat stress transcription factor world: how many heat stress transcription factors do we need? Cell Stress Chaperones 6:177 
Nover L, Scharf KD. (1997). Heat stress proteins and transcription factors. Cell Mol Life Sci 53:80

Nuhse TS, Peck SC, Hirt H, Boller T. (2000). Microbial elicitors induce activation and dual phosphorylation of the Arabidopsis thaliana MAPK 6. J Biol Chem 275:7521

Ouaked F, Rozhon W, Lecourieux D, Hirt H. (2003). A MAPK pathway mediates ethylene signaling in plants. Embo J 22:1282

Panchuk II, Volkov R.A, Schoffl F. (2002). Heat stress- and heat shock transcription factor-dependent expression and activity of ascorbate peroxidase in Arabidopsis. Plant Physiol 129:838

Pirkkala L, Nykanen P, Sistonen L. (2001). Roles of the heat shock transcription factors in regulation of the heat shock response and beyond. Faseb $\mathrm{J}$ 15:1118

Prandl R, Hinderhofer K, Eggers-Schumacher G, Schoffl, F. (1998). HSF3, a new heat shock factor from Arabidopsis thaliana, derepresses the heat shock response and confers thermotolerance when overexpressed in transgenic plants. Mol Gen Genet 258:269

Qiu JL, Zhou L, Yun BW, Nielsen HB, Fiil BK, Petersen K, Mackinlay J, Loake GJ, Mundy J, Morris PC. (2008). Arabidopsis mitogen-activated protein kinase kinases MKK1 and MKK2 have overlapping functions in defense signaling mediated by MEKK1, MPK4, and MKS1. Plant Physiol 148:212

Reindl A, Schoffl F. (1998). Interaction between the Arabidopsis thaliana heat shock transcription factor HSF1 and the TATA binding protein TBP. FEBS Lett 436:318 
Rentel MC, Lecourieux D, Ouaked F, Usher SL, Petersen L, Okamoto $\mathrm{H}$, Knight $\mathrm{H}$, Peck SC, Grierson CS, Hirt H, Knight MR. (2004). OXI1 kinase is necessary for oxidative burst-mediated signalling in Arabidopsis. Nature 427:858

Sangwan V, Dhindsa, RS. (2002). In vivo and in vitro activation of temperature-responsive plant map kinases. FEBS Lett 531:561

Scharf KD, Heider H, Hohfeld I, Lyck R, Schmidt E, Nover L. (1998). The tomato Hsf system: HsfA2 needs interaction with HsfA1 for efficient nuclear import and may be localized in cytoplasmic heat stress granules. Mol Cell Biol 18:2240

Scharf KD, Hohfeld I, Nover L. (1998). Heat stress response and heat stress transcription factors. J. Biosci. 23:313

Schoffl F, Prandl R, Reindl A. (1998). Regulation of the heat-shock response. Plant Physiol 117:1135

Schramm F, Ganguli A, Kiehlmann E, Englich G, Walch D, von Koskull-Doring, P. (2006). The heat stress transcription factor HsfA2 serves as a regulatory amplifier of a subset of genes in the heat stress response in Arabidopsis. Plant Mol Biol 60:759 Schramm F, Larkindale J, Kiehlmann E, Ganguli A, Englich G, Vierling E, von Koskull-Doring P. (2008). A cascade of transcription factor DREB2A and heat stress transcription factor HsfA3 regulates the heat stress response of Arabidopsis. Plant $\mathrm{J}$ $53: 264$

Schweighofer A, Kazanaviciute V, Scheikl E, Teige M, Doczi R, Hirt H, Schwanninger M, Kant M, Schuurink R, Mauch F, Buchala A, Cardinale F, Meskiene I. (2007). The PP2C-type phosphatase AP2C1, which negatively regulates MPK4 and MPK6, 
modulates innate immunity, jasmonic acid, and ethylene levels in Arabidopsis. Plant Cell 19:2213

Sörensson C, Lenman M, Veide-Vilg J, Schopper S, Ljungdahl T, Grøtli M, Tamás MJ, Peck SC, Andreasson E (2012). Determination of primary sequence specificity of Arabidopsis MAPKs MPK3 and MPK6 leads to identification of new substrates. Biochem J 446:271

Sorger P.K. (1990). Yeast heat shock factor contains separable transient and sustained response transcriptional activators. Cell 62:793

Sorger P.K. (1991). Heat shock factor and the heat shock response. Cell 65:363

Sorger P.K, Lewis M.J, Pelham H.R. (1987). Heat shock factor is regulated differently in yeast and HeLa cells. Nature 329:81

Sorger P.K, Pelham H.R. (1988). Yeast heat shock factor is an essential DNA-binding protein that exhibits temperature-dependent phosphorylation. Cell 54:855

Takahashi F, Mizoguchi T, Yoshida R, Ichimura K, Shinozaki K. (2011). Calmodulin-dependent activation of MAP kinase for ROS homeostasis in Arabidopsis. Mol Cell 41:649

Takahashi F, et al. (2007). The mitogen-activated protein kinase cascade MKK3-MPK6 is an important part of the jasmonate signal transduction pathway in Arabidopsis. Plant Cell 19:805

Tanoue T, Adachi M, Moriguchi T, Nishida E. (2000). A conserved docking motif in MAP kinases common to substrates, activators and regulators. Nat Cell Biol 2:110

Teige M, et al. (2004). The MKK2 pathway mediates cold and salt stress signaling in Arabidopsis. Mol Cell 15:141 
Topfer R, Schell J, Steinbiss HH. (1988). Versatile Cloning Vectors for Transient Gene-Expression and Direct Gene-Transfer in Plant-Cells. Nucleic Acids Res. $16: 8725$

Ulm R, Ichimura K, Mizoguchi T, Peck SC, Zhu T, Wang X, Shinozaki K, Paszkowski J. (2002). Distinct regulation of salinity and genotoxic stress responses by Arabidopsis MAP kinase phosphatase 1. Embo J 21:6483

Usami S, Ohta S, Komari, T, Burnell J.N. (1995). Cold stability of pyruvate, orthophosphate dikinase of Flaveria brownii. Plant Mol Biol 27:969

von Koskull-Doring P, Scharf K.D, Nover L. (2007). The diversity of plant heat stress transcription factors. Trends Plant Sci 12:452

Wang W, Vinocur B, Shoseyov O, Altman, A. (2004). Role of plant heat-shock proteins and molecular chaperones in the abiotic stress response. Trends Plant Sci $9: 244$

Wunderlich M, Werr W, Schoffl F. (2003). Generation of dominant-negative effects on the heat shock response in Arabidopsis thaliana by transgenic expression of a chimaeric HSF1 protein fusion construct. Plant J 35:442

Xing Y, Jia W, Zhang J. (2007). AtMEK1 mediates stress-induced gene expression of CAT1 catalase by triggering $\mathrm{H} 2 \mathrm{O} 2$ production in Arabidopsis. J Exp Bot 58:2969 Xing Y, Jia W, and Zhang J. (2009). AtMKK1 and AtMPK6 are involved in abscisic acid and sugar signaling in Arabidopsis seed germination. Plant Mol Biol 70:725 Yuasa T, Ichimura K, Mizoguchi T, Shinozaki K. (2001). Oxidative stress activates ATMPK6, an Arabidopsis homologue of MAP kinase. Plant Cell Physiol 42:1012 
Figure 1

Heat stress-induced MPK6 activation in Arabidopsis leaves.

\section{FIGURE 1}

A

hs (min)

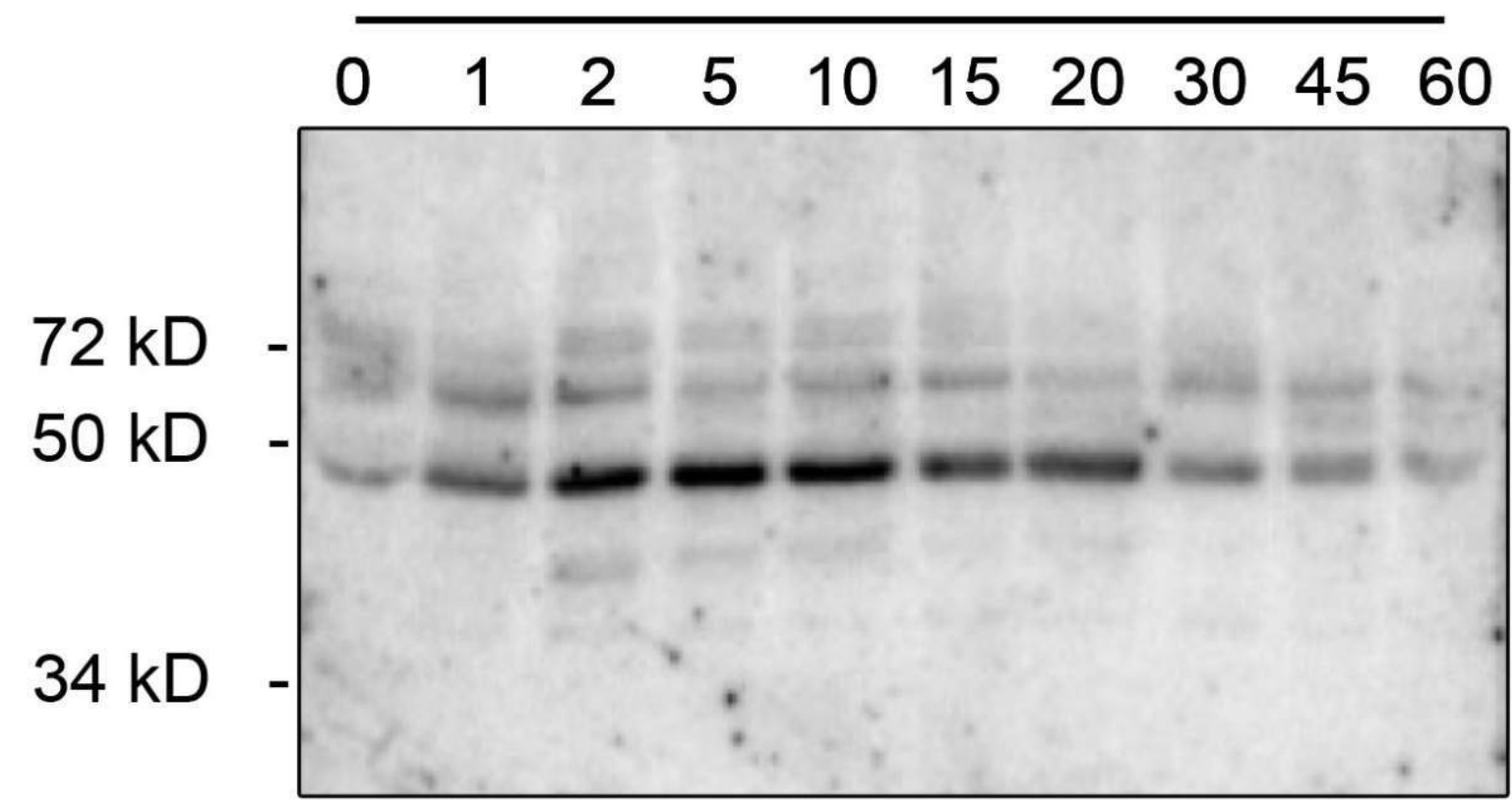

B

hs (min)

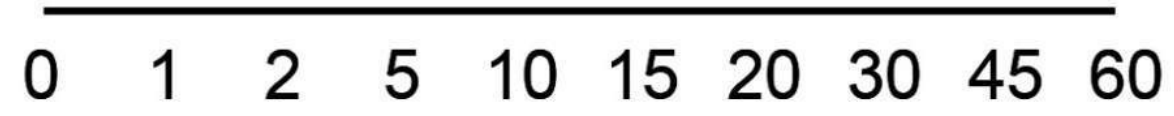

Activity

Protein 


\section{Figure 2}

In vitro phosphorylation of heat stress transcription factors by MPK6.

\section{FIGURE 2}

A

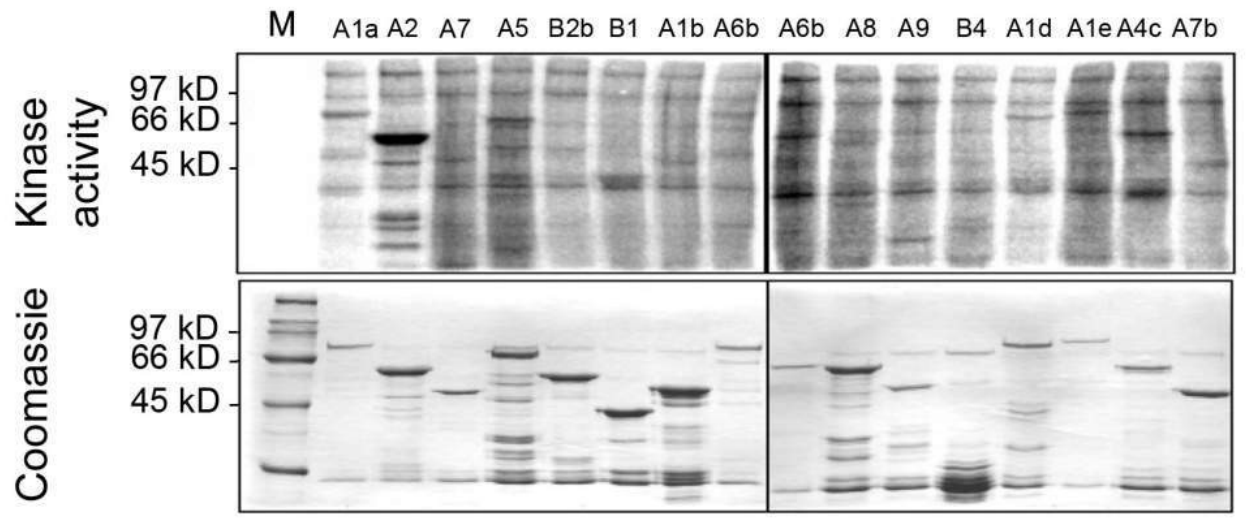

B

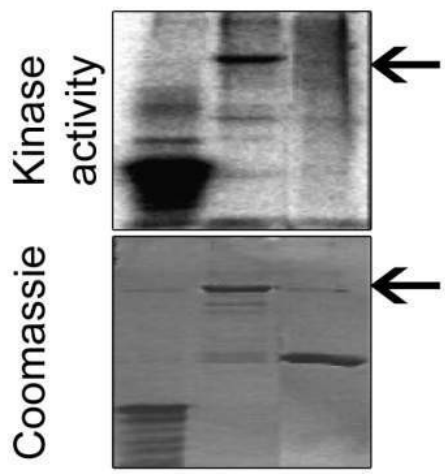


Figure 3

In vivo complex formation of MPK6 with HsfA2.

\section{FIGURE 3}

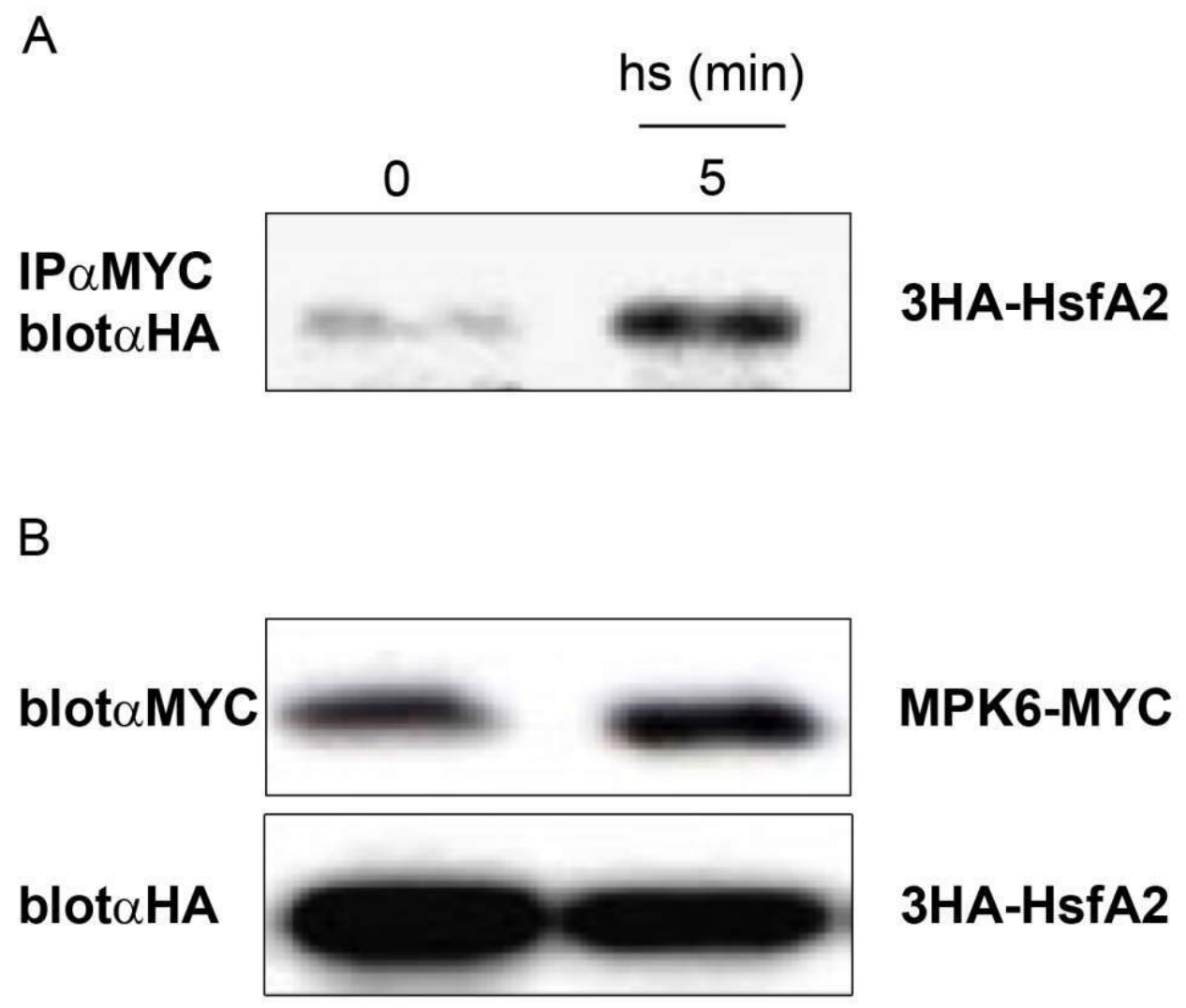




\section{Figure 4}

MPK6 phosphorylate HsfA2 on T249.

FIGURE 4

A
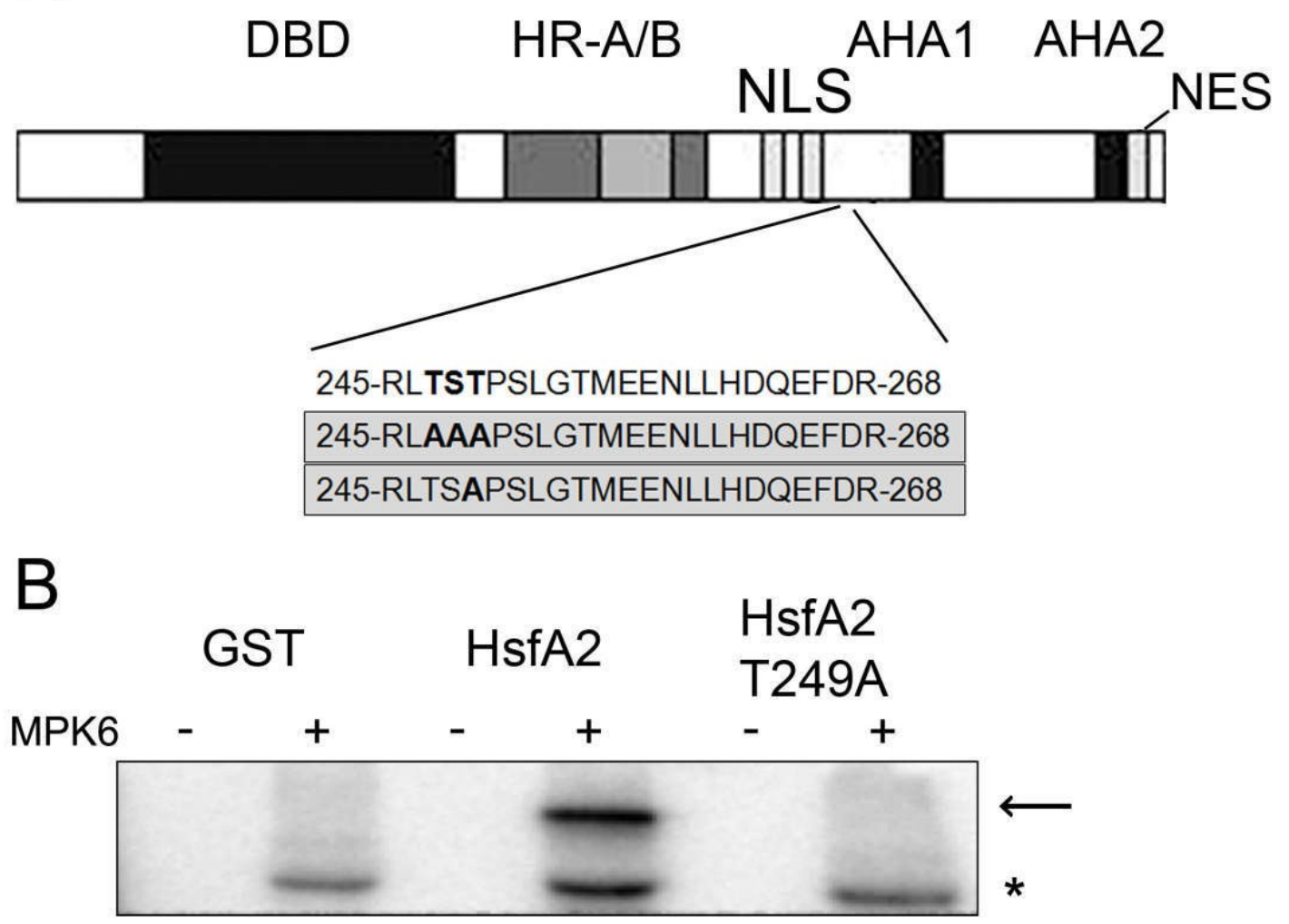


\section{Figure 5}

Analysis of the subcellular distribution of HsfA2 during a heat stress. 
Figure 5

A

HsfA2-WT

HsfA2-T249A

HsfA2-T249D

B

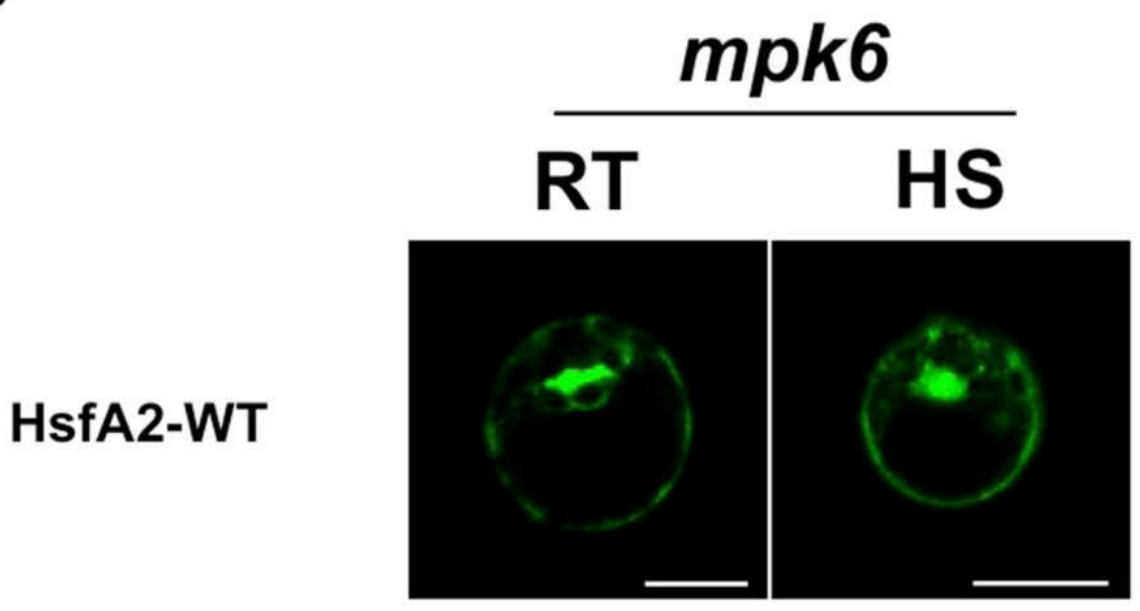




\section{Figure 6}

Protein kinase and phosphatase inhibitors affect the expression of heat stress-induced proteins. 
Figure 6

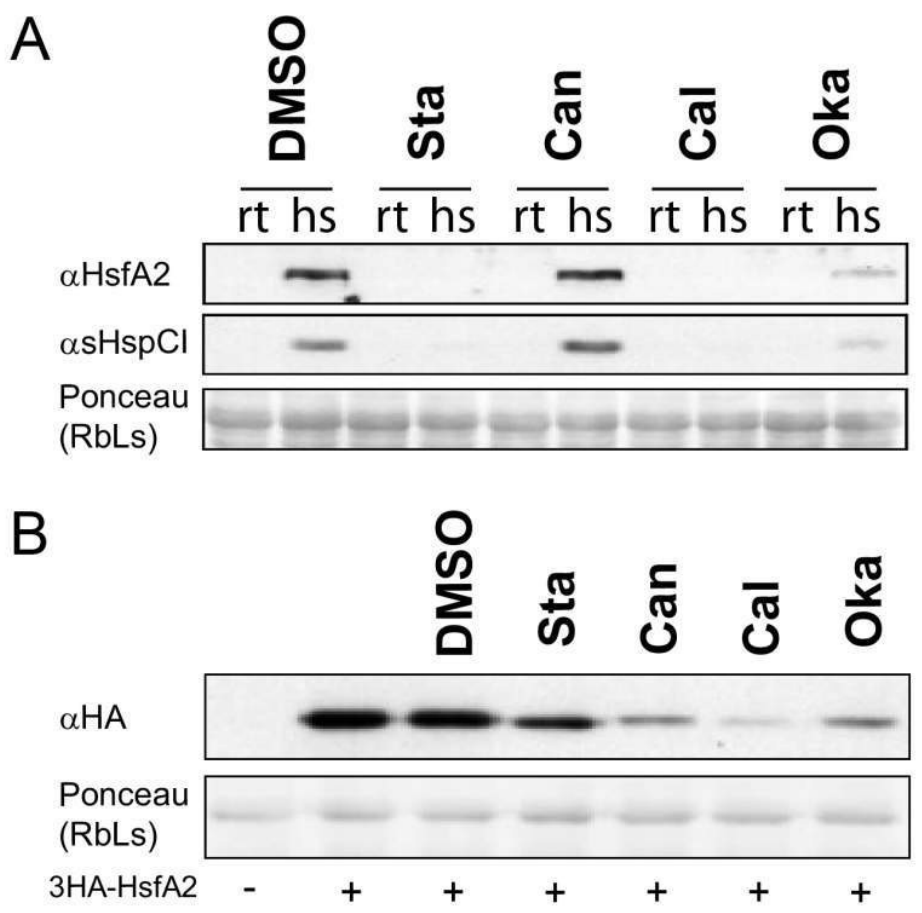

C

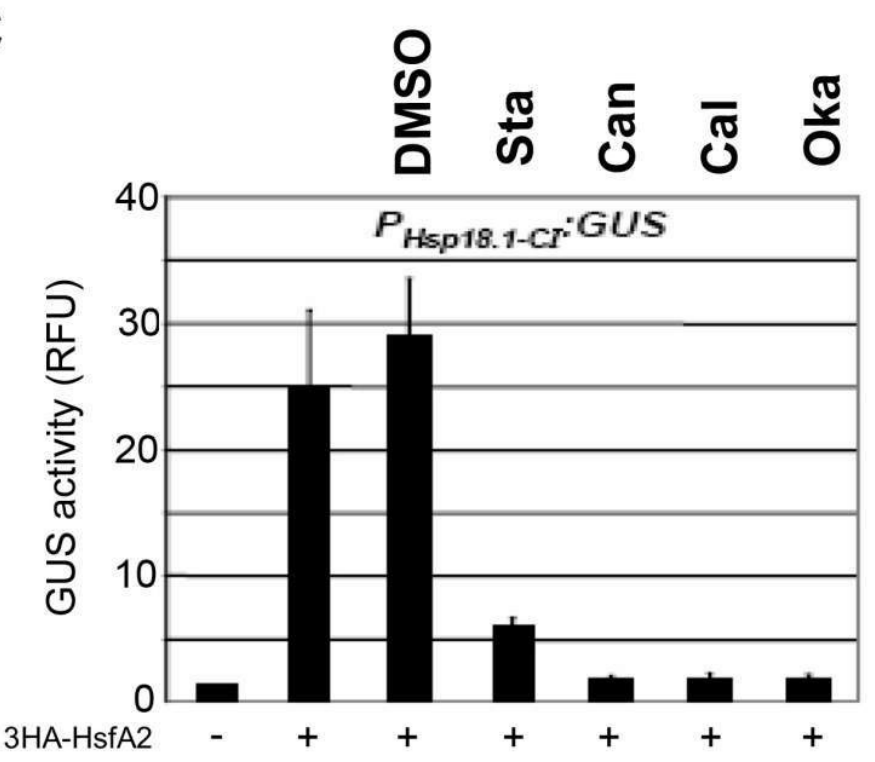


Figure 7

MPK6 does not regulate HsfA2 protein stability .

Figure 7

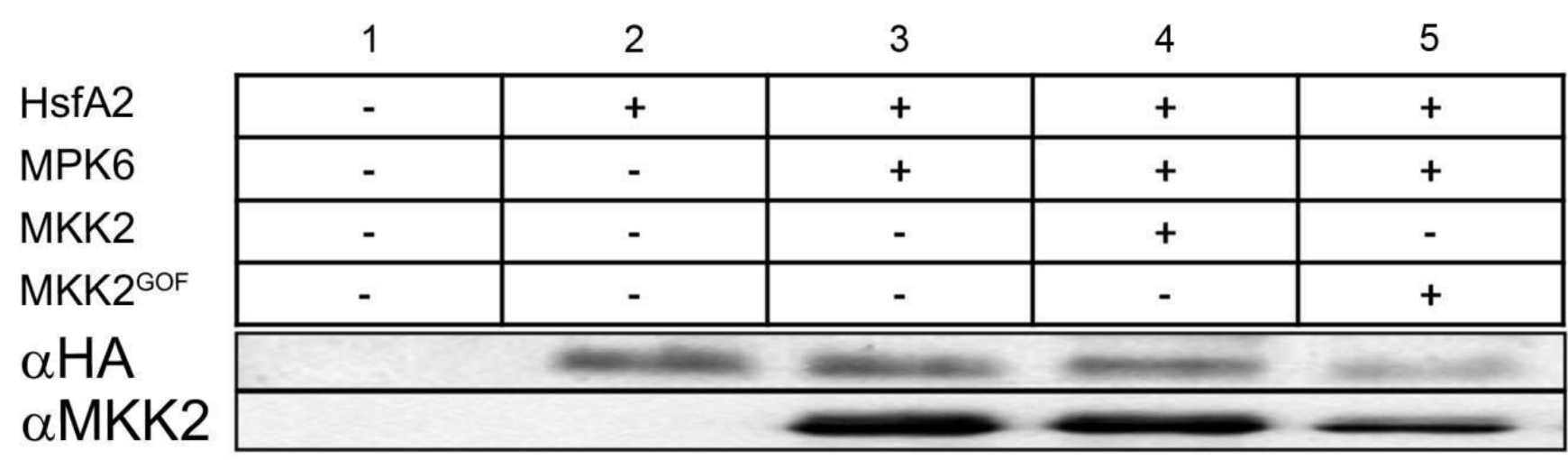

